\title{
Proposta metodológica para análise de viabilidade econômico- financeira da universalização e prestação dos serviços de saneamento básico
}

\author{
A new methodology for analyzing the economic and financial feasibility of \\ universalization and provision of basic sanitation services
}

Iran E. Lima Neto*

Data de entrada: 07/12/2012 | Data de aprovação: 03/04/2013

Resumo

Este artigo apresenta uma nova metodologia para análise de viabilidade econômico-financeira da universalização e prestação dos serviços de saneamento básico, considerando-se ampliações progressivas da cobertura desses serviços em cada área de planejamento. A metodologia considera ainda a disposição dos usuários a pagar pelos serviços, o que permite avaliar diferentes cenários de viabilidade a partir de diferentes combinações de receitas. A aplicação da metodologia ao município de Juazeiro do Norte/CE, adotado como estudo de caso, resultou em valores de investimentos para a universalização inferiores aos custos de capital, bem como em receitas referentes à prestação dos serviços inferiores aos custos de operação e manutenção, sendo que o cenário mais viável do ponto de vista econômico-financeiro foi a adoção de receitas dos setores de água e esgoto oriundas das prestadoras dos serviços e receitas dos setores de resíduos sólidos e drenagem urbana obtidas do estudo de disposição a pagar.

Palavras-chave: Custos; investimentos; planejamento; receitas; saneamento básico; viabilidade econômico-financeira.

\begin{abstract}
This paper presents a new methodology for analyzing the economic and financial feasibility of the universalization and provision of basic sanitation services, considering the increasing coverage of these services in each planning area. The methodology also considers the willingness of users to pay for the services, which allows evaluating different scenarios of feasibility from different combinations of incomes. The methodology was applied to the municipality of Juazeiro do Norte, in the State of Ceará, Brazil, as a case study, resulting in values for the investments lower than those for construction costs, as well as service incomes lower than the operation and maintenance costs, but with the more feasible scenario considering water and sewage incomes obtained from the basic sanitation companies, and solid waste and urban drainage incomes obtained from the study of willingness to pay.
\end{abstract}

Key-words: Basic sanitation; costs; economic and financial feasibility; incomes; investments; planning.

Iran E. Lima Neto*

Engenheiro Civil (UFC). Mestre em Hidráulica e Saneamento (EESC - USP). Ph.D. em Engenharia Hidráulica (University of Alberta/ Canadá). Professor Adjunto do Departamento de Engenharia Hidráulica e Ambiental da UFC.

*Endereço para correspondência: Campus do Pici, Bloco 713, $1^{\circ}$. andar, CEP 60.451-970, Fortaleza, Ceará Tel.: +55 85 3366-9491; Fax: +55 85 3366-9627

Email:iran@deha.ufc.br 


\section{Introdução}

A Lei Federal n ${ }^{\circ}$ 11.445/07 estabelece diretrizes nacionais para o saneamento básico, o qual é definido como o conjunto de serviços, infraestruturas e instalações operacionais de abastecimento de água potável, esgotamento sanitário, limpeza urbana e manejo de resíduos sólidos e drenagem e manejo das águas pluviais urbanas.

A referida Lei foi regulamentada pelo Decreto Federal $n^{\circ} 7.217 / 10$, que estabelece que a partir de 2014, a existência de plano de saneamento básico será condição para o acesso a recursos orçamentários da União ou a recursos de financiamentos geridos ou administrados por órgão ou entidade da administração pública federal, quando destinados ao setor. As legislações supracitadas destacam ainda a existência de estudo de viabilidade econômico-financeira da prestação dos serviços de saneamento básico, nos termos do respectivo plano, como uma das condições para validade dos contratos que tenham por objeto a prestação desses serviços. Em virtude disso, os Termos de Referência elaborados pela Fundação Nacional de Saúde - FUNASA para desenvolvimento de planos municipais de saneamento básico têm exigido a inclusão de estudos preliminares de viabilidade econômico-financeira da prestação universal e integral dos serviços (entre outros aspectos previstos pela Lei Federal $n^{\circ} 11.445 / 07$ e pelo Decreto Federal $n^{\circ}$ $7.217 / 10)$ nos referidos planos, conforme relatado por Lima Neto \& Santos (2011). No entanto, diversos planos de saneamento básico baseados em outros Termos de Referência têm sido elaborados desconsiderando-se tal análise de viabilidade ou, com raras exceções, apresentando análise restrita aos setores de abastecimento de água e esgotamento sanitário, sem levar em conta os setores de limpeza urbana/manejo de resíduos sólidos e drenagem/manejo das águas pluviais urbanas, nem possíveis variabilidades espaciais e temporais das receitas e dos custos de operação e manutenção (ver, por exemplo, os planos listados por Sobrinho, 2011). Além disso, os referidos planos normalmente não realizam análise de viabilidade econômico-financeira da universalização, ou seja, dos investimentos e custos previstos para ampliar progressivamente o acesso aos quatros setores do saneamento básico. Contudo, a importância dessa análise é mencionada, por exemplo, em Leoneti et al. (2011) e Vargas (2011).
Neste contexto, o presente trabalho tem como objetivo desenvolver uma proposta metodológica para análise de viabilidade econômico-financeira da prestação dos serviços de saneamento básico ao longo de cada etapa de planejamento e considerando-se as peculiaridades de cada área de planejamento, ou seja, diferentes condições de ampliação dos serviços, receitas e custos de operação e manutenção. A metodologia proposta considera ainda a disposição dos usuários a pagar pelos serviços, com base no trabalho de Silva (2011), que permite avaliar diferentes cenários de viabilidade econômico-financeira, incluindo receitas oriundas também dos setores de resíduos sólidos e drenagem urbana. Adicionalmente, a metodologia permite avaliar os custos de capital para investimentos na universalização do acesso ao saneamento básico, considerando também as variabilidades espaciais e temporais. Vale destacar que a metodologia proposta tem como base o Termo de Referência elaborado pela FUNASA e a Secretaria das Cidades do Estado do Ceará e o modelo de Lima Neto (2011) para planejamento da universalização e foi desenvolvida recentemente para a construção dos planos de saneamento básico de dez municípios da região do Cariri, no Ceará: Altaneira, Barbalha, Caririaçu, Crato, Farias Brito, Jardim, Juazeiro do Norte, Missão Velha, Nova Olinda e Santana do Cariri. Dessa forma, a exigência legal de existência de plano de saneamento básico e de análise de viabilidade econômico-financeira já pôde ser atendida na ocasião da elaboração dos planos supracitados.

\section{Metodologia}

\section{$1^{\circ}$. Passo - Definição de metas municipais para a universalização}

O $1^{\circ}$. Passo para o estudo de viabilidade econômico-financeira consiste na definição de metas para a universalização do saneamento básico, tanto nas zonas urbanas como rurais dos municípios.

Para as zonas urbanas, são definidas metas de ampliação dos índices de cobertura de cada serviço de saneamento básico a serem atingidas ao longo do horizonte de planejamento (no presente caso, 30 anos, conforme definido no Termo de Referência elaborado pela FUNASA e a Secretaria das Cidades do Estado do Ceará). 
Cabe salientar que essas metas são municipais e precisam posteriormente ser distribuídas em cada região político-administrativa (sede municipal e demais distritos), as quais foram consideradas como áreas de planejamento. Neste trabalho adotou-se o modelo de Lima Neto (2011) para realizar a hierarquização de áreas e o planejamento da universalização nas zonas urbanas, conforme será visto no $2^{\circ}$. Passo desta metodologia. A vantagem de se utilizar tal procedimento é eliminar eventuais subjetividades no processo de planejamento e promover aumentos nos índices de cobertura (em função de indicadores de prioridade) de mesma ordem de grandeza para diferentes áreas urbanas das sedes municipais e dos demais distritos, visando à compatibilização da prestação dos serviços, conforme preconizado na Lei Federal $n^{\circ}$ 11.445/07.

Para o setor de abastecimento de água nas zonas rurais, manteve-se a cobertura atual com rede de distribuição ao longo do horizonte de planejamento, o que significa dizer que as ampliações serão feitas em função do crescimento vegetativo da população. Da mesma forma, para o restante da população rural (difusa), considerou-se a manutenção da cobertura atual com soluções individuais, tais como cisternas, poços individuais e barragens subterrâneas (conforme apoiado pelo Decreto Federal $n^{0} 7.217 / 10$ ), ao longo do horizonte de planejamento. Ressalta-se, porém, que é possível incluir a implantação de novos sistemas públicos que por ventura venham a ser construídos em pequenas comunidades desprovidas de abastecimento de água coletivo, caso haja projetos de rede previstos para a zona rural. Caso contrário, essas possíveis modificações poderão ser contempladas nas fases de revisão do plano, conforme previsto na Lei Federal $n^{\circ} 11.445 / 07$. Para o setor de esgotamento sanitário nas zonas rurais, devido à ausência de rede e ao baixo nível de renda das comunidades avaliadas no presente estudo, adotou-se uma ampliação linear da cobertura com soluções individuais do tipo banheiro e sistema fossa-sumidouro, conforme apoiado pelo Decreto Federal n ${ }^{\circ} 7.217 / 10$, até se atingir o patamar de $100 \%$ em final de plano. $\mathrm{O}$ mesmo foi feito com relação à cobertura do serviço de coleta de resíduos sólidos na zona rural, conforme apoiado pelo Governo do Estado do Ceará. Por outro lado, não foram previstas metas de implantação do setor de drenagem e manejo das águas pluviais nas zonas rurais, já que a legislação federal prevê a cobertura desse serviço apenas nas zonas urbanas.

\section{$2^{\circ}$. Passo - Hierarquização de áreas e planeja- mento da universalização nas zonas urbanas}

$\mathrm{O} 2^{\circ}$. Passo para a elaboração do estudo de viabilidade econômico-financeira consistiu na hierarquização de prioridades entre as zonas urbanas das regiões político-administrativas e no planejamento da universalização do acesso ao saneamento básico nessas áreas, utilizando o modelo desenvolvido por Lima Neto (2011). Esse procedimento foi necessário uma vez que os custos de investimentos para universalização bem como os custos de operação e manutenção da prestação dos serviços de saneamento básico podem diferir significativamente entre diferentes áreas de planejamento. Como resultado, obtém-se o planejamento da ampliação dos índices de cobertura de cada setor do saneamento básico, considerando metas imediatas (até 5 anos), de curto prazo (6 a 10 anos), médio prazo (11 a 20 anos) e longo prazo (21 a 30 anos), conforme definido no Termo de Referência elaborado pela FUNASA e a Secretaria das Cidades do Estado do Ceará. Salienta-se que em virtude da baixa população urbana dos distritos avaliados neste estudo, considerou-se a universalização do setor de esgotamento sanitário nestas áreas em uma única etapa de planejamento (médio ou longo prazo). Vale destacar que a implantação em uma única etapa de sistemas de esgotamento sanitário em zonas urbanas de pequenos distritos é prática comum no Estado do Ceará.

Embora o procedimento de hierarquização e planejamento da universalização para cada região político-administrativa tenha sido realizado apenas para as zonas urbanas, é importante mencionar que um procedimento semelhante ao descrito anteriormente também poderá ser realizado posteriormente para as zonas rurais, à medida que se dispuser de dados nas fases de revisão dos planos de saneamento básico. Portanto, uma das principais ações que devem ser propostas nos planos é a realização de levantamento detalhado da cobertura dos serviços de abastecimento de água, esgotamento sanitário, limpeza urbana e manejo de resíduos sólidos nas zonas rurais, incluindo tanto as comunidades existentes como a população difusa. 
$3^{\circ}$. Passo - Viabilidade econômico-financeira da universalização e prestação dos serviços

$03^{\circ}$. Passo consiste na análise de viabilidade econômico-financeira da universalização e prestação dos serviços de saneamento básico utilizando os resultados apresentados nos passos anteriores. Dessa forma, é realizada análise de viabilidade através de comparação entre custos de capital e investimentos previstos para a universalização, assim como entre custos de operação e manutenção e receitas financeiras referentes à prestação dos serviços. Os valores são estimados em moeda de dezembro de 2012. Assim, os dados de natureza econômico-financeira poderão ser atualizados para tal data de referência com base no Índice Nacional de Preços ao Consumidor Amplo - IPCA.

\section{Análise dos custos de capital e investimentos previstos para a universalização}

A estimativa de custos de capital para a universalização do acesso ao saneamento básico foi realizada considerando-se separadamente três áreas: zona urbana das sedes municipais, zona urbana dos demais distritos e zona rural.

Para as zonas urbanas foram adotadas projeções de crescimento populacional (para os setores de abastecimento de água, esgotamento sanitário, limpeza urbana e manejo de resíduos sólidos) e de crescimento das áreas urbanas (para o setor de drenagem e manejo das águas pluviais urbanas), bem como as projeções de coberturas dos serviços obtidas a partir do $2^{\circ}$. Passo da metodologia.

Os custos unitários de capital para investimento nos setores de abastecimento de água potável e esgotamento sanitário nas zonas urbanas ( $\mathrm{R} \$ /$ habitante) se referem a valores médios obtidos a partir de projetos realizados nos últimos dez anos na região do Cariri e no Estado do Ceará. O custo unitário do setor de limpeza urbana e manejo de resíduos sólidos ( $\mathrm{R} \$ /$ habitante) se refere ao valor médio obtido do Estudo de Viabilidade do Programa para o Tratamento e Disposição de Resíduos Sólidos do Estado do Ceará (PROINTEC, 2005). O custo unitário do setor de drenagem e manejo de águas pluviais urbanas $\left(\mathrm{R} \$ / \mathrm{km}^{2}\right)$ foi estimado a partir de dados disponíveis em Tucci (2005) e no $10^{\circ}$ Balanço do Programa de Aceleração do Crescimento do Governo Federal (PAC) para o Estado do Ceará. Salienta-se que os valores médios para cada setor do saneamento básico foram apresentados de acordo com três categorias: áreas de pequeno, médio e grande porte, conforme detalhado no Plano Municipal de Saneamento Básico de Juazeiro do Norte (Juazeiro, 2012). Dessa forma, dependendo do porte de seus distritos, o mesmo município pode conter até três diferentes custos unitários para cada setor do saneamento básico.

Para a zona rural foram adotadas as projeções de crescimento populacional para os setores de abastecimento de água, esgotamento sanitário e limpeza urbana e manejo de resíduos sólidos, bem como as projeções de coberturas dos serviços obtidas a partir do $1^{\circ}$. Passo da metodologia. Neste caso, considerou-se tanto a ampliação de sistemas coletivos de abastecimento de água como de soluções individuais para os setores de água e esgoto, além da ampliação da coleta de resíduos sólidos.

Os custos unitários de capital para investimento em soluções coletivas para o setor de água e soluções individuais para os setores de água e esgoto na zona rural ( $\mathrm{R} \$ /$ habitante) se referem a valores médios obtidos a partir de projetos implantados ou em implantação no Estado do Ceará e na região do Cariri. O custo unitário do setor de limpeza urbana e manejo de resíduos sólidos ( $\mathrm{R} \$ /$ habitante) foi novamente obtido a partir do Estudo de Viabilidade do Programa para o Tratamento e Disposição de Resíduos Sólidos do Estado do Ceará (PROINTEC, 2005).

Os investimentos referem-se aos valores relacionados à universalização dos serviços de saneamento básico, com base no conceito legal de ampliação progressiva. No presente estudo, adotou-se o Plano Plurianual - PPA do Estado do Ceará para o período de 2012-2015 como base para a previsão dos investimentos a serem aportados aos municípios. Como no referido PPA não havia um valor específico para investimento em saneamento básico em cada município envolvido neste estudo, considerou-se que o valor total anual para investimento no setor seria repassado proporcionalmente para cada município em função da relação entre a sua população e a população do Estado do Ceará. É importante destacar que alternativamente também podem ser utilizadas outras fontes para avaliação dos investimentos previstos para a universalização tais como balanços do PAC ou planos plurianu- 
ais nas esferas municipal e nacional.

Por fim, a análise de viabilidade econômico-financeira com relação à ampliação progressiva dos serviços de saneamento básico em cada município foi realizada através de comparação entre os custos de capital e os investimentos previstos ao longo do horizonte de planejamento. O resultado dessa comparação permite a avaliação da necessidade de captação de recursos financeiros adicionais para se garantir a universalização dos serviços. Cabe salientar que os custos de capital obtidos podem ser utilizados também para a elaboração de planos de investimentos em saneamento básico (exigência da Lei Federal $n^{\circ}$ 11.445/07) em cada área de planejamento, conforme detalhado no Plano Municipal de Saneamento Básico de Juazeiro do Norte (Juazeiro, 2012).

\section{Análise dos custos de operação e manutenção e receitas referentes à prestação dos serviços}

Os custos de operação e manutenção correspondem aos dispêndios relacionados à prestação dos serviços (incluindo a gestão), considerando valores obtidos através de pesquisa acerca de tais custos para cada setor do saneamento básico, praticados nos municípios em questão. A estimativa desses custos foi realizada considerando-se separadamente três áreas: zona urbana das sedes municipais, zona urbana dos demais distritos e zona rural. Nas zonas rurais dos municípios, devido à existência de modelo de autogestão do Sistema Integrado de Saneamento Rural - SISAR, cuja operação e manutenção dos sistemas de abastecimento de água é de responsabilidade da própria comunidade, seus custos e receitas foram considerados em equilíbrio econômico-financeiro. Da mesma forma, os setores de esgoto e drenagem foram desconsiderados da análise de custos e receitas, uma vez que não são previstas medidas estruturais coletivas para as zonas rurais. Portanto, apenas o setor de resíduos sólidos foi considerado na análise de custos e receitas nas zonas rurais dos municípios.

Os valores referentes aos custos anuais com operação e manutenção dos sistemas de abastecimento de água e esgotamento sanitário $(\mathrm{R} \$$ / habitante/ano) foram projetados a partir dos valores das despesas por habitante atendido pelos mencionados serviços, conforme dados apresentados no Sistema Nacional de Informa- ções sobre Saneamento - SNIS ou fornecidos diretamente pela Companhia de Água e Esgoto do Ceará - CAGECE, pelos Serviços Autônomos de Água e Esgoto - SAAE ou pelas Prefeituras Municipais. Os valores referentes ao setor de limpeza urbana e manejo de resíduos sólidos ( $\mathrm{R} \$ /$ habitante/ano) também foram estimados a partir das despesas por habitante atendido, conforme dados disponibilizados pelas Prefeituras Municipais. Na ausência de informações mais detalhadas para os municípios em questão, os custos anuais com operação e manutenção do setor de drenagem e manejo de águas pluviais urbanas $\left(\mathrm{R} \$ / \mathrm{km}^{2} / \mathrm{ano}\right)$ foram estimados em aproximadamente 5\% dos custos de capital, conforme sugerido por Tucci (2005).

Para a projeção de receitas dos serviços de saneamento básico nas zonas urbanas e rurais, foram consideradas três alternativas como referência:

Alternativa 1: Receitas oriundas apenas dos serviços de abastecimento de água e esgotamento sanitário operados pela CAGECE, pelo SAAE e/ou pela Prefeitura Municipal.

Alternativa 2: Receitas obtidas de estudo de disposição a pagar por cada serviço do saneamento básico, conduzido em cada área de planejamento com base em Silva (2011). Tal estudo foi realizado como forma simplificada e participativa de se estimar a capacidade de pagamento dos usuários nos quatro setores do saneamento básico.

Alternativa 3: Receitas de água e esgoto oriundas da CAGECE, do SAAE e/ou da Prefeitura Municipal e receitas dos serviços de resíduos sólidos e drenagem urbana oriundas do estudo de disposição a pagar.

Finalmente, a análise de viabilidade econômico-financeira foi feita em cada município através da comparação entre os custos de operação e manutenção e as receitas oriundas da prestação dos serviços de saneamento básico, de acordo com as três alternativas supracitadas. O resultado dessa comparação permite avaliar qual das alternativas é a mais viável do ponto de vista econômico-financeiro. Além disso, os valores obtidos a partir da metodologia supracitada permitem ainda a análise da condição de sustentabilidade e equilíbrio econômico-financeiro da prestação dos serviços. Como resultado, o Plano Municipal de Saneamento Básico de Juazeiro do Norte (Juazeiro, 2012) fornece, por exem- 
plo, valores de receitas médias ( $\mathrm{R} \$$ habitante) para se atingir a referida condição de sustentabilidade e equilíbrio econômico-financeiro ao longo do horizonte de planejamento.

\section{Resultados e discussão}

Conforme mencionado anteriormente, a metodologia proposta foi adotada na elaboração dos planos de saneamento básico de dez municípios localizados na região do Cariri, no Estado do Ceará. Entretanto, no presente artigo, serão apresentados apenas os resultados referentes ao maior município da região, isto é, Juazeiro do Norte.

\section{Metas municipais para a universalização}

As metas municipais para a universalização do saneamento básico em Juazeiro do Norte foram obtidas com base no $1^{\circ}$. Passo da metodologia apresentada anteriormente. Assim, para as zonas urbanas, incluindo a sede de Juazeiro do Norte e os seus distritos de Padre Cícero e Marrocos, conforme estabelecido pelos grupos de trabalho envolvidos na elaboração do Plano Municipal de Saneamento Básico - PMSB, os índices de cobertura dos serviços de saneamento básico a serem atingidos ao final do planejamento de 30 anos são de $100 \%$, sendo que a universalização dos serviços de abastecimento de água e limpeza urbana e manejo dos resíduos sólidos já é prevista para o horizonte imediato de 5 anos, enquanto que a universalização dos serviços de esgotamento sanitário e drenagem e de manejo das águas pluviais urbanas é prevista para 20 e 30 anos, respectivamente, conforme apresentado na Figura 1.

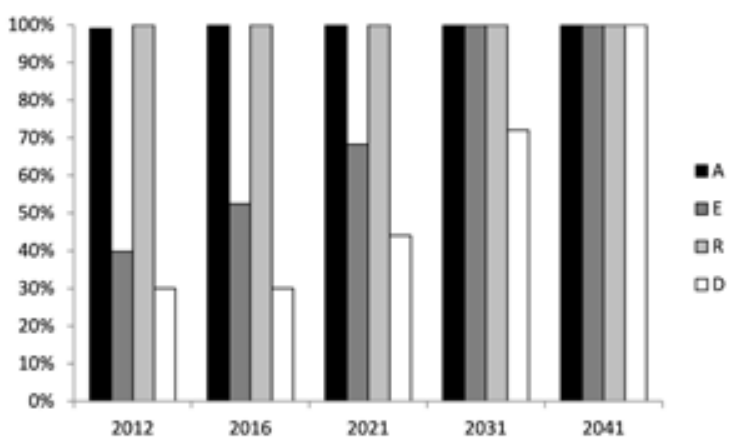

Figura 1- Metas de crescimento dos índices de cobertura das zonas urbanas do município de Juazeiro do Norte ( $A$ - água, $E$ - esgoto, $R$ - resíduos sólidos e $D$-drenagem urbana).
Para o setor de abastecimento de água nas zonas rurais do município de Juazeiro do Norte, manteve-se a cobertura com rede de distribuição de $19 \%$ e a cobertura com soluções individuais de $81 \%$ ao longo do horizonte de planejamento, conforme indicado na Figura 2.

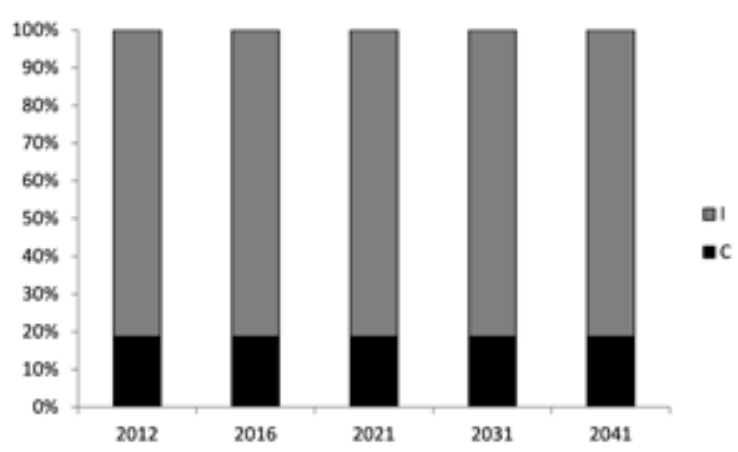

Figura 2 - Metas para o setor de abastecimento de água na zona rural do município de Juazeiro do Norte (I - soluções individuais do tipo cisternas, poços individuais e barragens subterrâneas; $C$ - soluções coletivas do tipo rede de abastecimento de água).

Para o setor de esgotamento sanitário nas zonas rurais, considerou-se a ampliação linear da cobertura com soluções individuais do tipo banheiro e sistema fossa-sumidouro. Logo, conforme mostrado na Figura 3, a cobertura variará de 3 a 100\% ao longo do horizonte de planejamento.

Para o setor de resíduos sólidos nas zonas rurais, considerou-se a ampliação linear da co-

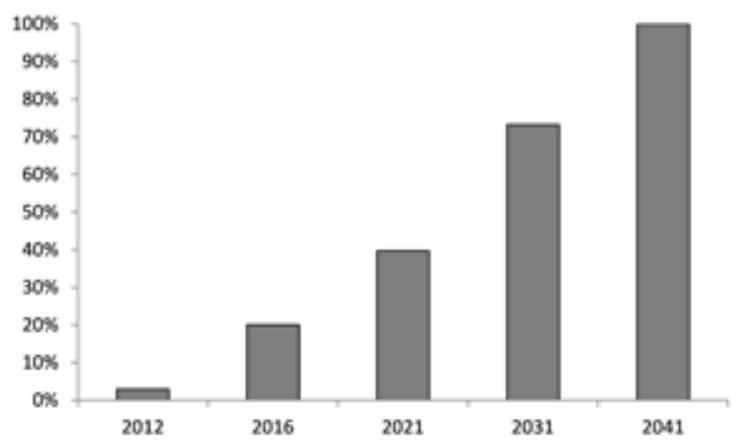

Figura 3 - Metas para o setor de esgotamento sanitário na zona rural do município de Juazeiro do Norte. 


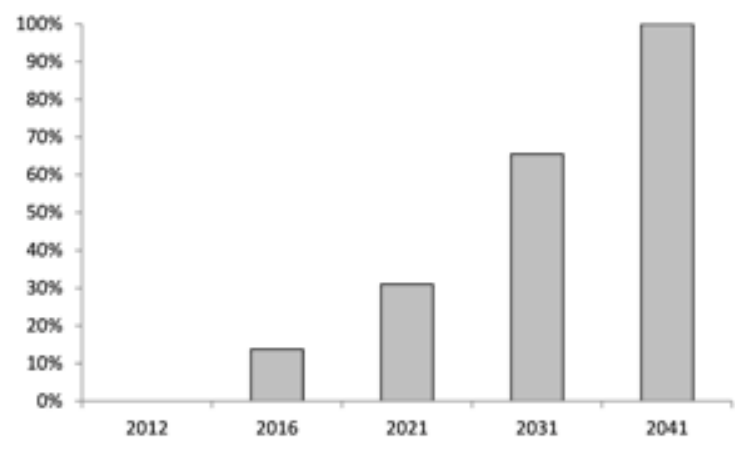

Figura 4 - Metas para o setor de resíduos sólidos na zona rural do município de Juazeiro do Norte.

bertura do serviço de coleta. A Figura 4 mostra uma variação da cobertura de 0 a $100 \%$ ao longo do horizonte de planejamento.

\section{Planejamento da universalização nas zonas urbanas}

A hierarquização de áreas urbanas da sede de Juazeiro do Norte e dos distritos de Padre Cícero e Marrocos e o planejamento da universalização do saneamento básico em cada uma dessas áreas foram feitos com base no $2^{\circ}$. Passo da metodologia. As Figuras 5 a 9 apresentam a situação atual dos índices de cobertura das áreas consideradas bem como o planejamento da ampliação desses índices obtido a partir da aplicação do modelo de Lima Neto (2011), adotando-se metas imediatas, de curto, médio e longo prazo. Vale ressaltar que em virtude da baixa população urbana dos distritos de Padre Cícero e Marrocos, considerou-se a universalização do setor de esgotamento sanitário nestas

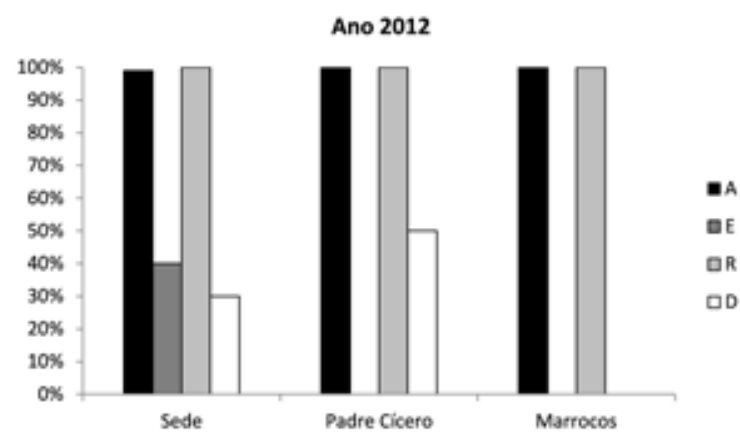

Figura 5 - Situação atual dos índices de cobertura relativos a cada setor do saneamento básico no município de Juazeiro do Norte ( $A$ - água, E - esgoto, $R$ - resíduos sólidos e D drenagem urbana).

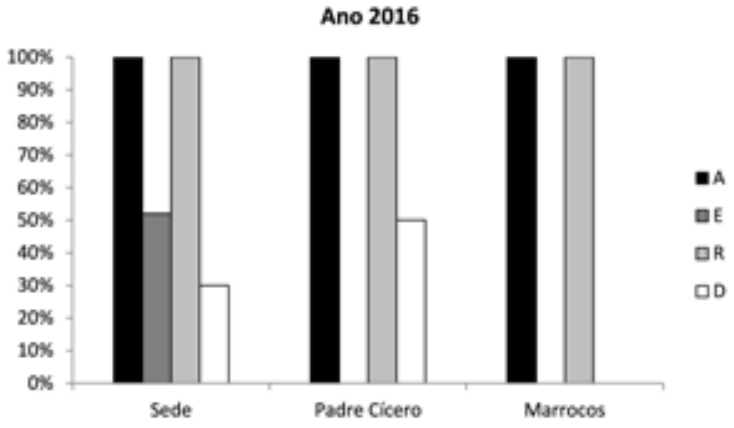

Figura 6 - Metas imediatas (até 5 anos) para os índices de cobertura relativos a cada setor do saneamento básico no município de Juazeiro do Norte ( $A$ - água, E - esgoto, $R$ resíduos sólidos e $D$-drenagem urbana).

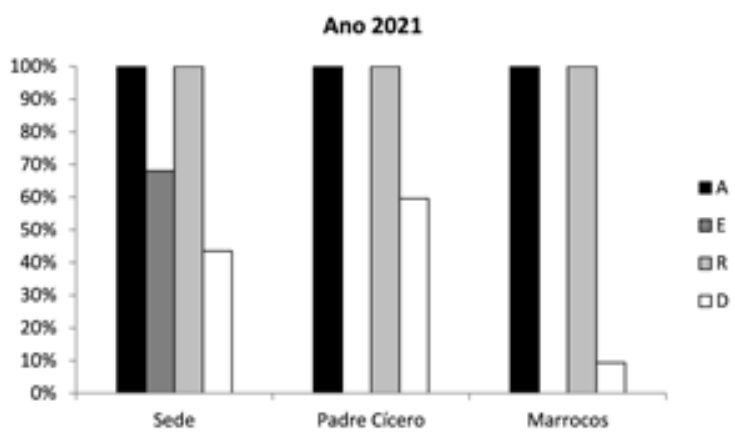

Figura 7 - Metas de curto prazo (6 a 10 anos) para os indices de cobertura relativos a cada setor do saneamento básico no município de Juazeiro do Norte ( $A$ - água, E esgoto, $R$ - resíduos sólidos e $D$ - drenagem urbana).

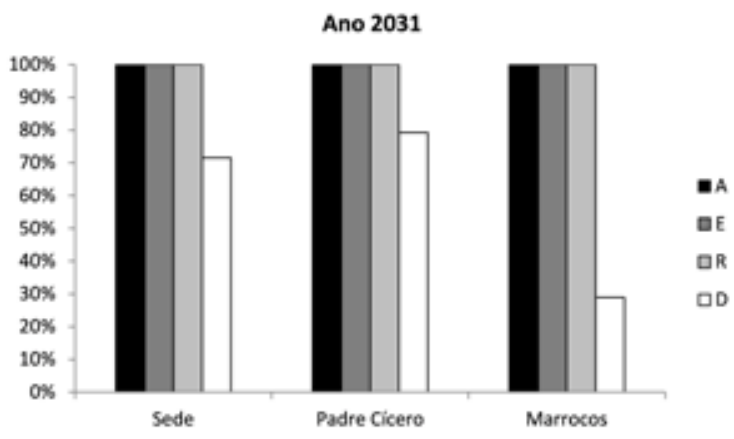

Figura 8 - Metas de médio prazo (11 a 20 anos) para os índices de cobertura relativos a cada setor do saneamento básico no município de Juazeiro do Norte (A - água, E esgoto, $R$ - resíduos sólidos e $D$ - drenagem urbana). 


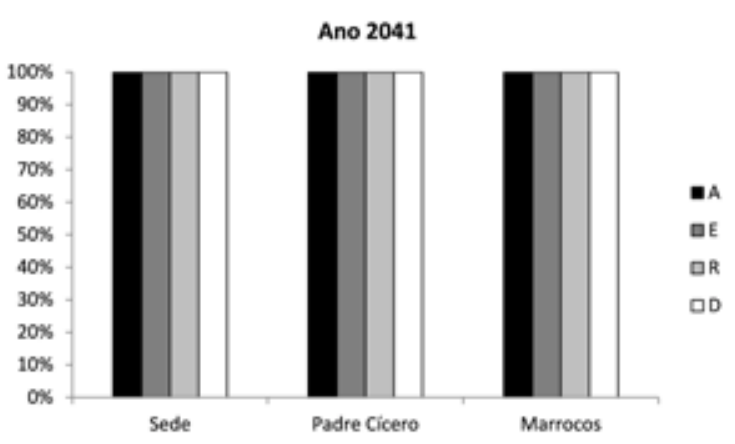

Figura 9 - Metas de longo prazo (21 a 30 anos) para os índices de cobertura relativos a cada setor do saneamento básico no município de Juazeiro do Norte (A - água, E esgoto, $R$ - resíduos sólidos e $D$ - drenagem urbana).

áreas em uma única etapa de planejamento (entre 11 e 20 anos), logo após a universalização do acesso na sede municipal (que obteve maior peso na hierarquização devido principalmente à sua elevada população urbana).

\section{Viabilidade econômico-financeira}

A análise de viabilidade com relação à universalização do saneamento básico no município de Juazeiro do Norte foi realizada com base no $3^{\circ}$. Passo da metodologia. A Figura 10 mostra que no final do horizonte de planejamento o custo total de capital acumulado (incluindo os custos relacionados aos setores de água, esgoto, resíduos sólidos e drenagem urbana) é cerca de $45 \%$ superior ao investimento previsto (obtido a partir do PPA do Estado do Ceará), o que indica a necessidade de captação de recursos financeiros adicionais para se garantir a universalização dos serviços. Diversos possíveis mecanismos de financiamento para o saneamento básico são apresentados por Leoneti et al. (2011) e Dietrich (2011), por exemplo. Ressalta-se que resultados similares aos apresentados na Figura 10 foram obtidos para os demais municípios da região do Cariri envolvidos no estudo. No entanto, em alguns casos os custos de capital foram inferiores aos investimentos previstos, demostrando assim uma condição favorável à universalização dos serviços.

A análise de viabilidade com relação à prestação dos serviços de saneamento básico no município de Juazeiro do Norte também foi realizada com base no $3^{\mathrm{a}}$. Passo da metodologia. Os resultados são mostrados nas Figuras 11, 12 e 13,

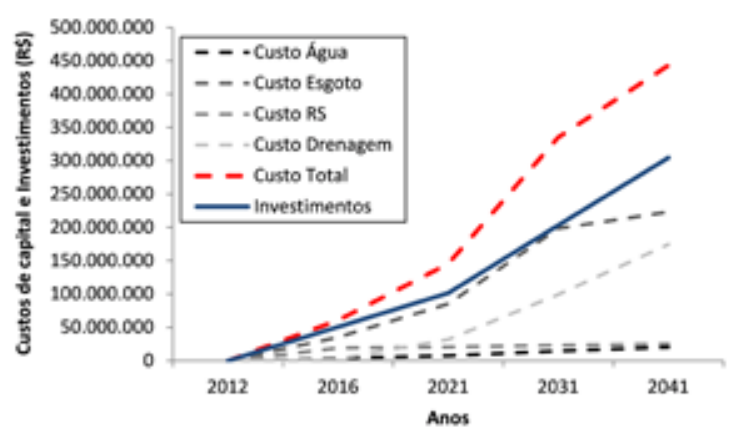

Figura 10 - Análise de viabilidade com relação à universalização do saneamento básico no município de Juazeiro do Norte (valores acumulados para os custos de capital e investimentos previstos).

onde os custos de operação e manutenção são comparados às receitas referentes às Alternativas 1,2 e 3 , respectivamente. Observa-se que no caso da Alternativa 1 (receitas dos setores de água e esgoto oriundas das prestadoras dos serviços) os custos de operação e manutenção superam as receitas entre aproximadamente $42 \mathrm{e}$ $52 \%$ (ver Figura 11). Já no caso da Alternativa 2 (receitas dos quatro setores oriundas do estudo de disposição a pagar) os custos de operação e manutenção são entre 2,8 e 3,0 vezes superiores às receitas (ver Figuras 12). Por fim, no caso da Alternativa 3 (receitas dos setores de água e esgoto oriundas das prestadoras dos serviços e receitas dos setores de resíduos sólidos e drenagem urbana oriundas do estudo de disposição a pagar) os custos de operação e manutenção superam as receitas entre 21 e 26\% (ver Figuras

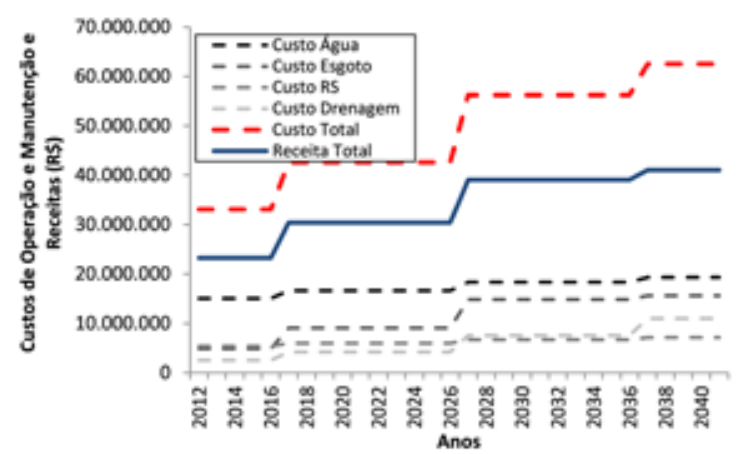

Figura 11 - Análise de viabilidade com relação à prestação dos serviços de saneamento básico no município de Juazeiro do Norte (valores para os custos de operação e manutenção e receitas considerando a Alternativa 1). 


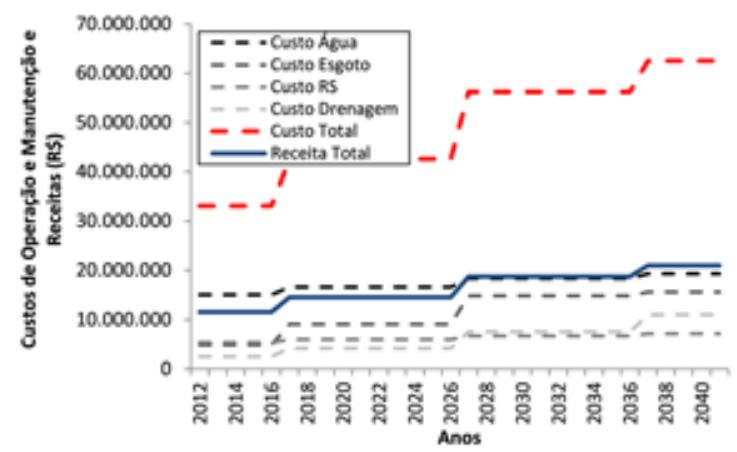

Figura 12 - Análise de viabilidade com relação à prestação dos serviços de saneamento básico no município de Juazeiro do Norte (valores para os custos de operação e manutenção e receitas considerando a Alternativa 2).

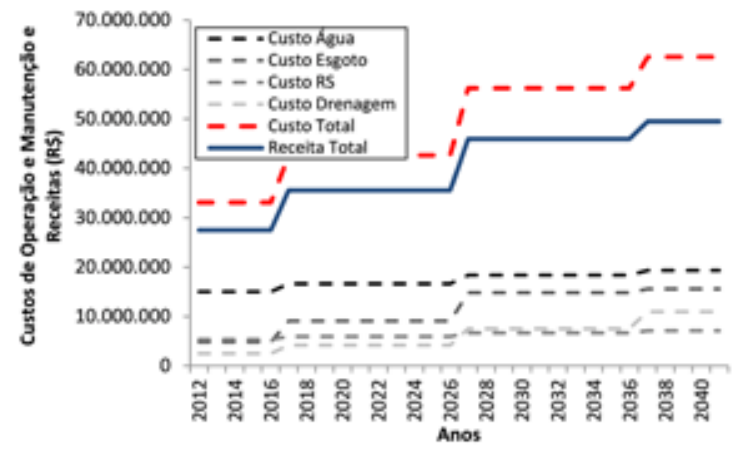

Figura 13 - Análise de viabilidade com relação à prestação dos serviços de saneamento básico no município de Juazeiro do Norte (valores para os custos de operação e manutenção e receitas considerando a Alternativa 3).

13), o que sugere que esta alternativa se configura como uma opção mais viável do ponto de vista econômico-financeiro. Todavia, ressalta-se a necessidade de se realizar estudos mais aprofundados sobre tarifas e políticas de subsídios (ver Bontes, 2011, por exemplo), visando à sustentabilidade e o equilíbrio econômico-financeiro da prestação dos serviços, em conformidade com os princípios da Lei Federal $n^{\circ}$ $11.445 / 07$. Vale salientar que resultados similares aos apresentados nas Figuras 11 a 13 foram obtidos para os demais municípios do Cariri analisados, sendo que em alguns casos os custos de operação e manutenção considerando-se a Alternativa 3 foram imediatamente inferiores às receitas, demostrando dessa forma uma condição favorável à sustentabilidade e ao equilíbrio econômico-financeiro da prestação dos serviços.

\section{Conclusões}

Este trabalho teve como objetivo desenvolver uma metodologia para análise de viabilidade econômico-financeira da universalização e prestação dos serviços de saneamento básico, considerando-se ampliações progressivas da cobertura desses serviços em cada área de planejamento. A metodologia leva em consideração ainda a disposição dos usuários a pagar pelos serviços de saneamento básico, o que permite a avaliação de diferentes cenários de viabilidade econômico-financeira da prestação dos serviços, incluindo receitas oriundas não apenas dos setores de água e esgoto, mas também dos setores de limpeza urbana e manejo de resíduos sólidos e drenagem e manejo das águas pluviais urbanas. Portanto, pode-se dizer que a presente metodologia se configura como uma forma mais completa de se analisar a viabilidade econômico-financeira do saneamento básico em cada município, já que as outras metodologias em uso normalmente se limitam à análise dos setores de água e esgoto, sem levar em conta os setores de resíduos sólidos e drenagem urbana, nem possíveis variabilidades espaciais e temporais inerentes ao processo de planejamento.

A metodologia proposta foi desenvolvida recentemente para a elaboração dos planos de saneamento básico dos municípios de Altaneira, Barbalha, Caririaçu, Crato, Farias Brito, Jardim, Juazeiro do Norte, Missão Velha, Nova Olinda e Santana do Cariri, localizados na região do Cariri do Estado do Ceará. Adotando Juazeiro do Norte como estudo de caso, pôde-se observar que os investimentos previstos para a universalização foram inferiores aos custos de capital, assim como as receitas referentes à prestação dos serviços foram inferiores aos custos de operação e manutenção. Cabe salientar que o cenário mais favorável do ponto de vista econômico-financeiro da prestação dos serviços foi à adoção de receitas dos setores de água e esgoto oriundas das prestadoras dos serviços e receitas dos setores de resíduos sólidos e drenagem urbana oriundas do estudo de disposição a pagar. Em síntese, os resultados obtidos indicam não apenas a necessidade de captação de recursos financeiros adicionais para se garantir a universalização dos serviços, mas também de reavaliação das tarifas atualmente praticadas no município e/ou adoção de novas políticas de subsídios para se promover a sustentabilidade e 
o equilíbrio econômico-financeiro da prestação dos serviços.

Finalmente, a metodologia apresentada neste trabalho poderá ser adotada tanto na elaboração de novos planos de saneamento básico como nas fases de revisão dos mesmos, visando atender a exigência legal de existência dos referidos planos e de análise de viabilidade econômico-financeira. Salienta-se também que a metodologia proposta poderá servir ainda como base para a realização de análise de viabilidade econômico-financeira mais aprofundada, incluindo, por exemplo, índices econômicos como valor presente líquido e ponto de equilíbrio entre outros aspectos que venham a ser relevantes.

\section{Referências}

BONTES, A. G. Tarifas e Subsídios dos Serviços de Saneamento Básico. In: Gestão do Saneamento Básico: Abastecimento de Água e Esgotamento Sanitário. Philippi Jr., A.; Galvão Júnior, A. C., Manole, 751-781, 2011.

DIETRICH, J. L. Mecanismos de Financiamento para o Saneamento Básico. In: Gestão do Saneamento Básico: Abastecimento de Água e Esgotamento Sanitário. Philippi Jr., A.; Galvão Júnior, A. C., Manole, 782-819, 2011.

JUAZEIRO DO NORTE. Plano Municipal de Saneamento Básico de Juazeiro do Norte/CE. Fundação Nacional de Saúde - FUNASA/Secretaria das Cidades/Estado do Ceará, 2012.

LEONETI, A. B.; PRADO, E. L.; OLIVEIRA, S. V. W. B. Saneamento Básico no Brasil: Considerações sobre Investimentos e Sustentabilidade para o Século XXI. Revista de Administração Pública, Rio de Janeiro, 45(2): 331-348, 2011.

LIMA NETO, I. E. Planejamento no Setor de Saneamento Básico considerando o Retorno da Sociedade. Revista DAE, n. 8, 46-52, 2011.

LIMA NETO, I. E.; SANTOS, A. B. Planos de Saneamento Básico. In: Gestão do Saneamento Básico: Abastecimento de Água e Esgotamento Sanitário. Philippi Jr., A.; Galvão Júnior, A. C., Manole, 57-79, 2011.

PROINTEC. Estudo de Viabilidade do Programa para o Tratamento e Disposição de Resíduos Sólidos do Estado do Ceará. Secretaria das Cidades/Estado do Ceará, 2005.
SILVA, F. O. Plano de Águas Municipal como Instrumento de Política Pública para a Universalização do Abastecimento de Pequenas Comunidades Rurais do Semiárido Cearense. Tese de Doutorado, Universidade Federal do Ceará UFC, 2011.

SOBRINHO, G. B. Planos Municipais de Saneamento Básico (PMSB): Instrumento para Universalização do Abastecimento de Água e do Esgotamento Sanitário. Dissertação de Mestrado, Universidade Federal do Ceará - UFC, 2011.

TUCCI, C. E. M. Gestão de Águas Pluviais Urbanas. Ministério das Cidades, Global Water Partnership, World Bank/Unesco, 2005.

VARGAS, M. C. Universalização dos Serviços de Saneamento Básico. In: Gestão do Saneamento Básico: Abastecimento de Água e Esgotamento Sanitário. Philippi Jr., A.; Galvão Júnior, A. C., Manole, 721-750, 2011. 